\title{
Manipulation of Adenosine Kinase Affects Sleep Regulation in Mice
}

\author{
Svitlana Palchykova, ${ }^{1}$ Raphaelle Winsky-Sommerer, ${ }^{1}$ Hai-Ying Shen, ${ }^{2}$ Detlev Boison, ${ }^{2}$ Andrea Gerling, ${ }^{1}$ \\ and Irene Tobler ${ }^{1}$ \\ ${ }^{1}$ Institute of Pharmacology and Toxicology, University of Zurich, CH-8057 Zurich, Switzerland, and 2Robert Stone Dow Neurobiology Laboratories, Legacy \\ Research, Portland, Oregon 97232
}

Sleep and sleep intensity are enhanced by adenosine and its receptor agonists, whereas adenosine receptor antagonists induce wakefulness. Adenosine kinase (ADK) is the primary enzyme metabolizing adenosine in adult brain. To investigate whether adenosine metabolism or clearance affects sleep, we recorded sleep in mice with engineered mutations in Adk. Adk-tg mice overexpress a transgene encoding the cytoplasmic isoform of ADK in the brain but lack the nuclear isoform of the enzyme. Wild-type mice and $A d k^{+/-}$mice that have a $50 \%$ reduction of the cytoplasmic and the nuclear isoforms of ADK served as controls. Adk-tg mice showed a remarkable reduction of EEG power in low frequencies in all vigilance states and in theta activity $(6.25-11 \mathrm{~Hz})$ in rapid eye movement (REM) sleep and waking. $A d k$-tg mice were awake 58 min more per day than wild-type mice and spent significantly less time in REM sleep (102 \pm 3 vs $128 \pm 3$ min in wild type). After sleep deprivation, slow-wave activity $(0.75-4 \mathrm{~Hz})$, the intensity component of non-rapid eye movement sleep, increased significantly less in Adk-tg mice and their slow-wave energy was reduced. In contrast, the vigilance states and EEG spectra of $A d k^{+/-}$and wild-type mice did not differ. Our data suggest that overexpression of the cytoplasmic isoform of ADK is sufficient to alter sleep physiology. ADK might orchestrate neurotransmitter pathways involved in the generation of EEG oscillations and regulation of sleep.

\section{Introduction}

The neuromodulator adenosine plays a key role in sleep regulation (Radulovacki, 1985; Benington and Heller, 1995; Basheer et al., 2004; Datta and Maclean, 2007; Huang et al., 2007; Scharf et al., 2008). Adenosine and adenosine receptor agonists enhance non-rapid eye movement (NREM) and rapid eye movement (REM) sleep (Marley and Nistico, 1972; Haulică et al., 1973; Snyder et al., 1981; Virus et al., 1983; Radulovacki et al., 1985; Sarda et al., 1986; Martin et al., 1989; Ticho and Radulovacki, 1991; Portas et al., 1997). Moreover, the adenosine agonist cyclopentyladenosine enhanced EEG slow-wave activity (SWA) (power between 0.75 and $4 \mathrm{~Hz}$ ) (Benington et al., 1995; Schwierin et al., 1996). Adenosine receptor antagonists (caffeine, cyclopentyltheophylline) induce wakefulness (Yanik et al., 1987; Biaggioni et al., 1991; Landolt et al., 1995; Schwierin et al., 1996; Huang et al., 2005). The effects of adenosine on sleep are mediated by adenosine $\mathrm{A}_{1}$ (Basheer et al., 2001; Thakkar et al., 2003; Alanko et al.,

Received March 16, 2010; revised July 16, 2010; accepted Aug. 5, 2010.

This work was supported by Swiss National Science Foundation Grant 3100A0-112528/1, European Union (EU) Grant LSHM-CT-2005-518189, EU Grant MCRTN-CT-2004-512362, and National Institute of Mental Health Grant R01-MH83973. We thank Dr. P. Achermann for advice in data analysis and Drs. A. Borbély, V. Vyazovskiy, and L. Tarokh for critical comments on this manuscript.

Correspondence should be addressed to Prof. Irene Tobler, Institute of Pharmacology and Toxicology, University of Zurich, Winterthurerstrasse 190, CH-8057 Zurich, Switzerland. E-mail: tobler@pharma.uzh.ch.

R. Winsky-Sommerer's present address: Faculty of Health and Medical Sciences, University of Surrey, Guildford, Surrey GU2 7XH, United Kingdom.

A. Gerling's present address: Interfaculty Institute for Biochemistry, University of Tuebingen, D-72076 Tuebingen, Germany.

DOI:10.1523/JNEUROSCI.1359-10.2010

Copyright $\odot 2010$ the authors $\quad 0270-6474 / 10 / 3013157-09 \$ 15.00 / 0$
2004; Bjorness et al., 2009) and $\mathrm{A}_{2 \mathrm{~A}}$ receptors (Hayaishi et al., 2004). Inhibition of gliotransmission attenuated the accumulation of sleep pressure through $A_{1}$ receptors (Halassa et al., 2009).

Despite its ubiquitous presence, some studies indicated a role of adenosine in sleep in specific brain regions. The basal forebrain was suggested to gate sleep via adenosinergic inhibition of wakepromoting cholinergic neurons (Porkka-Heiskanen et al., 1997, 2000; Strecker et al., 2000). However, stimulation of adenosine receptors in other regions (e.g., hypothalamus) also induced sleep (Satoh et al., 1998, 1999; Scammell et al., 2001; Gallopin et al., 2005; Methippara et al., 2005; Oishi et al., 2008).

A little explored avenue in sleep is the in vivo manipulation of adenosine kinase (ADK), the primary enzyme regulating adenosine metabolism in rodents (Mathews et al., 1998; Boison, 2006). Inhibition of ADK activity induced a larger adenosine increase in hippocampal and cortical slices than adenosine deaminase inhibition (Pak et al., 1994; Lloyd and Fredholm, 1995; White, 1996). Moreover, adenosine release was higher in ADK-deficient fibroblasts compared with adenosine deaminase-deficient fibroblasts (Huber et al., 2001). Sleep deprivation (SD) had no effect on ADK activity in the cortex and basal forebrain, but the diurnal variation of ADK activity (Chagoya de Sánchez et al., 1993; Alanko et al., 2003) was maximal in the cortex (Mackiewicz et al., 2003).

Here, we used mice constitutively overexpressing a transgene for the cytoplasmic isoform of $A d k$ ( $A d k$-tg). These mutants are characterized by increased ADK enzyme activity and reduced adenosine tone in the brain (Fedele et al., 2005). Based on the reduced adenosine tone, mutants display spontaneous intrahippocampal seizures (Li et al., 2007, 2008a,b), increased susceptibility 


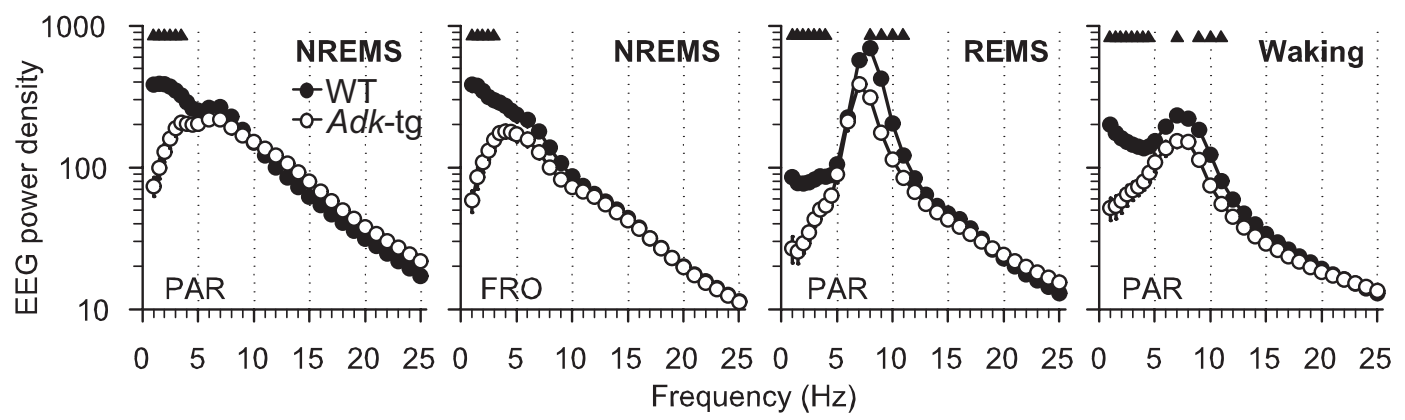

Figure 1. EEG power density in microvolt square per hertz ( $0.75-25 \mathrm{~Hz}$ ) in NREM sleep (NREMS), REM sleep (REMS), and waking in WT (black dots; $n=14)$ and $A d k$-tg mice (white dots; $n=11$ ) during the $24 \mathrm{~h}$ baseline. Shown are the mean values of the parietal (PAR) and frontal (FRO) EEG. Triangles, Genotype differences ( $p<0.05$ for NREMS PAR and waking; $p<0.01$ for NREMS FRO and REMS; Bonferroni's adjustment for multiple comparisons).

to stroke or seizure-induced neuronal cell death (Pignataro et al., 2007), and cognitive impairment (Yee et al., 2007). We hypothesized that the transgene overexpression in Adk-tg mice should affect sleep. As controls, we chose $A d k^{+/-}$mice, which have reduced ADK in the liver, but normal adenosine metabolites (Boison et al., 2002) and wild-type (WT) littermates. The mice were subjected to $6 \mathrm{~h} \mathrm{SD}$ to stimulate sleep regulatory mechanisms.

\section{Materials and Methods}

Animals. Adult heterozygous male mice originating from a targeted disruption of the $A d k$-gene $\left(A d k^{+/-}\right)$, maintained on a mixed 129/JEms $\times$ C57BL/ 6 background (for characterization, see Boison et al., 2002), and WT littermates were obtained by heterozygous breeding $\left(n=15 \mathrm{Adk}^{+/-} ; n=14 \mathrm{WT}\right.$ mice $)$. Mice overexpressing the cytoplasmic isoform of $\mathrm{ADK}$ were derived by rescuing the lethal phenotype of $A d k^{-1-}$ mice by introducing a

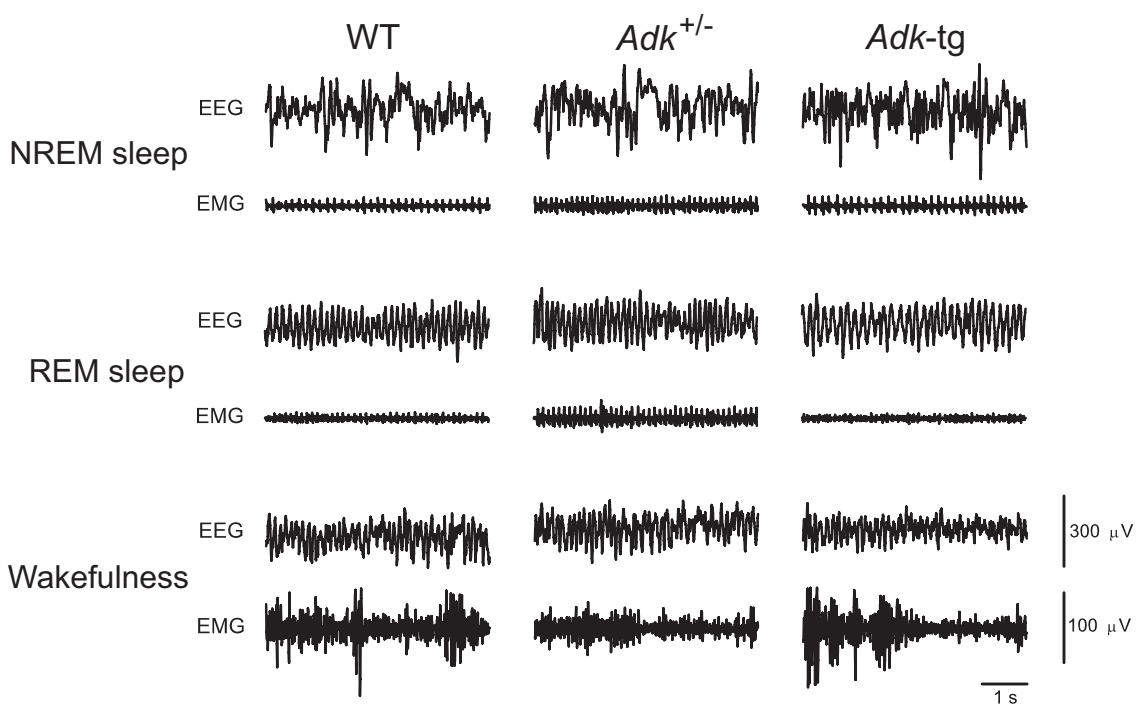

Figure 2. Representative $5 \mathrm{~s}$ raw parietal EEG and EMG traces during NREM sleep, REM sleep, and waking in WT, $A_{d k^{+/-}}$, and Adk-tg mice.

UbiAdk transgene into the $A d k^{-1-}$ back-

ground (Fedele et al., 2005) and maintained by homozygous breeding of $A d k$-tg mice $(n=11)$. The mice were kept individually in Macrolon cages $(36 \times 20 \times 35 \mathrm{~cm})$ with food and water available ad libitum, maintained

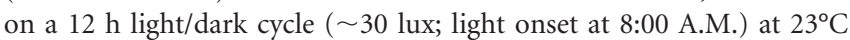
ambient temperature. The Cantonal Veterinary Office of Zurich approved all experimental procedures.

Surgery: EEG/EMG electrode implantation. Mice were implanted epidurally with gold-plated miniature screws $(0.9 \mathrm{~mm}$ diameter $)$ for EEG recording under isoflurane anesthesia [right hemisphere: above the frontal (FRO), $1.5 \mathrm{~mm}$ anterior to bregma, $2 \mathrm{~mm}$ lateral to the midline, and the parietal cortex (PAR), $2 \mathrm{~mm}$ posterior to bregma, $3 \mathrm{~mm}$ lateral to midline; reference: above the cerebellum, $2 \mathrm{~mm}$ posterior to lambda, on the midline]. Two gold wires ( $0.2 \mathrm{~mm}$ diameter) were inserted bilaterally into the neck muscles for EMG recording. The electrodes were connected to stainless-steel wires fixed to the skull with dental acrylic cement. The mice were connected by a fine cable to a swivel and remained connected throughout the experiment. At least 3 weeks were allotted for recovery from surgery and a minimum of $3 \mathrm{~d}$ for habituation to the recording chambers before data collection.

Experimental protocols. Recordings were performed during a $24 \mathrm{~h}$ baseline followed by $6 \mathrm{~h}$ SD starting at light onset and $18 \mathrm{~h}$ recovery. SD was performed by directly observing the mice and introducing new material into the cage (e.g., nesting material, wood or cardboard pieces) whenever a mouse appeared to be drowsy. If necessary, acoustic stimulation was used by gentle tapping on the cage (Tobler et al., 1997). Special care was taken not to interfere with eating and drinking behavior. Data were collected from frontal and parietal EEG derivations, because slow waves and spindles in NREM sleep are more prominent in the frontal EEG, whereas theta activity in waking and REM sleep is prominent in the parietal EEG.

A separate batch of $A d k$-tg $(n=12)$ and WT mice $(n=11)$ were placed in single cages equipped with an infrared sensor mounted above the cage for undisturbed, continuous motor activity recordings for 10 consecutive days (Chronobiology kit; Stanford Software Systems).

Data acquisition and analysis. The EEG and EMG signals were amplified (amplification factor, $\sim 2000$ ), conditioned by analog filters (highpass filter: $-3 \mathrm{~dB}$ at $0.016 \mathrm{~Hz}$; low-pass filter: $-3 \mathrm{~dB}$ at $40 \mathrm{~Hz}$, less than $-35 \mathrm{~dB}$ at $128 \mathrm{~Hz}$ ) sampled with $512 \mathrm{~Hz}$, digitally filtered [EEG: low-pass finite impulse response (FIR) filter, $25 \mathrm{~Hz}$; EMG: bandpass FIR filter, $20-50 \mathrm{~Hz}$ ], and stored with a resolution of $128 \mathrm{~Hz}$. The EEG power spectra were computed for $4 \mathrm{~s}$ epochs by a fast Fourier transform routine. Adjacent $0.25 \mathrm{~Hz}$ bins were averaged into $0.5 \mathrm{~Hz}(0.25-5 \mathrm{~Hz})$ and $1.0 \mathrm{~Hz}$ $(5.25-25 \mathrm{~Hz})$ bins. The EMG was full-wave rectified and integrated over 4 s epochs; ambient temperature within the animal cage was sampled at $4 \mathrm{~s}$ intervals. Before each recording, the EEG and EMG channels were calibrated with a $10 \mathrm{~Hz}, 300 \mu \mathrm{V}$ peak-to-peak sine wave.

The three vigilance states NREM sleep, REM sleep, and waking were determined off-line by visual inspection of the parietal and frontal EEG, EMG records and EEG power in the slow-wave range $(0.75-4 \mathrm{~Hz})$ for $4 \mathrm{~s}$ epochs. Epochs containing EEG artifacts in one derivation were excluded from spectral analyses of both EEG derivations $(6.3 \pm 0.6 \%$ of recording time, which occurred mainly during active waking). Vigilance states could always be determined. The frequency and duration of vigilance state episodes was computed using the methods of Deboer et al. (1994). Sleep continuity was assessed by determining the number of brief awak- 
Table 1. Amount of vigilance states

\begin{tabular}{|c|c|c|c|c|c|c|}
\hline & \multicolumn{2}{|l|}{ WT $(n=14)$} & \multicolumn{2}{|c|}{$A d k^{+1-}(n=15)$} & \multicolumn{2}{|l|}{$\operatorname{Adk}-\operatorname{tg}(n=11)$} \\
\hline & Baseline & SD and recovery & Baseline & SD and recovery & Baseline & SD and recovery \\
\hline \multicolumn{7}{|l|}{ NREM sleep } \\
\hline $24 \mathrm{~h}$ value & $738.3 \pm 16.5$ & $576.9 \pm 12.8^{* * *}$ & $752.1 \pm 12.7$ & $593.0 \pm 9.2^{* * *}$ & $706.3 \pm 8.3$ & $568.8 \pm 7.0^{* * *}$ \\
\hline L 1-6/SD & $200.7 \pm 5.0$ & $8.2 \pm 1.8$ & $209.9 \pm 4.2$ & $12.2 \pm 2.1$ & $215.3 \pm 5.3$ & $0.1 \pm 0.1$ \\
\hline L 7-12 & $202.0 \pm 4.7$ & $217.8 \pm 3.5^{*}$ & $204.4 \pm 3.4$ & $217.0 \pm 3.4^{* *}$ & $214.7 \pm 3.6$ & $237.5 \pm 3.1^{\# \#}$ \\
\hline D 13-18 & $147.6 \pm 6.5$ & $164.9 \pm 6.4^{*}$ & $148.7 \pm 7.2$ & $169.1 \pm 4.7^{* *}$ & $113.9 \pm 5.8^{\# \#}$ & $148.2 \pm 5.4$ \\
\hline D 19-24 & $187.9 \pm 5.2$ & $185.6 \pm 5.0$ & $189.1 \pm 4.3$ & $193.8 \pm 3.5$ & $162.5 \pm 5.7^{\#}$ & $183.0 \pm 5.8$ \\
\hline \multicolumn{7}{|l|}{ REM sleep } \\
\hline $24 \mathrm{~h}$ value & $128.0 \pm 3.1$ & $102.1 \pm 2.5^{* * *}$ & $123.0 \pm 3.4$ & $101.9 \pm 2.5^{* * *}$ & $102.4 \pm 3.3^{\# \#}$ & $81.3 \pm 3.2^{* * * \text {,\#\# }}$ \\
\hline L 1-6/SD & $34.7 \pm 1.3$ & $0 \pm 0$ & $35.1 \pm 1.6$ & $0.1 \pm 0.1$ & $31.9 \pm 1.4$ & $0.0 \pm 0$ \\
\hline L 7-12 & $41.4 \pm 1.1$ & $39.5 \pm 1.5$ & $39.4 \pm 1.0$ & $40.1 \pm 1.5$ & $36.5 \pm 1.2^{\#}$ & $34.9 \pm 1.4$ \\
\hline D 13-18 & $20.2 \pm 1.5$ & $29.0 \pm 1.6^{* * *}$ & $17.7 \pm 1.3$ & $28.7 \pm 1.1^{* * *}$ & $12.0 \pm 1.3^{\# \#}$ & $21.2 \pm 1.8^{* * *}$ \\
\hline D $19-24$ & $31.9 \pm 1.3$ & $33.6 \pm 1.0$ & $30.7 \pm 1.1$ & $33.1 \pm 1.2$ & $22.0 \pm 1.8^{\# \#}$ & $25.2 \pm 1.9$ \\
\hline \multicolumn{7}{|l|}{ Waking } \\
\hline $24 \mathrm{~h}$ value & $573.7 \pm 16.8$ & $761.0 \pm 14.0^{* * *}$ & $564.9 \pm 13.8$ & $745.1 \pm 9.5^{* * *}$ & $631.3 \pm 8.8^{\#}$ & $789.9 \pm 8.4^{* * *}$ \\
\hline L 1-6/SD & $124.6 \pm 5.6$ & $351.8 \pm 1.8$ & $115.0 \pm 4.9$ & $347.8 \pm 2.1$ & $112.8 \pm 6.2$ & $359.9 \pm 0.1$ \\
\hline L 7-12 & $116.6 \pm 4.8$ & $102.8 \pm 4.3^{*}$ & $116.2 \pm 3.5$ & $102.9 \pm 3.8^{* *}$ & $108.8 \pm 3.5$ & $87.6 \pm 3.5^{\#}$ \\
\hline D 13-18 & $192.2 \pm 7.3$ & $166.0 \pm 7.4^{*}$ & $193.6 \pm 8.0$ & $162.2 \pm 5.4^{* *}$ & $234.2 \pm 7.0^{\# \#}$ & $190.6 \pm 6.9^{\#}$ \\
\hline D 19-24 & $140.2 \pm 5.8$ & $140.8 \pm 5.5$ & $140.1 \pm 4.8$ & $133.2 \pm 3.9$ & $175.5 \pm 6.8^{\# \#}$ & $151.8 \pm 7.0$ \\
\hline
\end{tabular}

Mean values \pm SEM as minutes of NREM sleep, REM sleep, and waking in WT, $A d k^{+/-}$, and Adk-tg mice for 6 and $24 \mathrm{~h}$ intervals during a baseline day and a day consisting of $6 \mathrm{~h} \mathrm{SD}$ followed by $18 \mathrm{~h}$ recovery. L, Light; $\mathrm{D}$, dark. Differences between the baseline and experimental day: ${ }^{*} p<0.05,{ }^{* *} p<0.005$, and ${ }^{* * *} p<0.0001$, paired $t$ test following significant ANOVA interaction repeated "day: BL versus recovery" by repeated "three $6 \mathrm{~h}$ intervals" for NREMS, REMS, and waking ( $p<0.005)$. In Adk-tg mice, interaction for NREMS and waking was nonsignificant, but repeated-factor "day" was $p<0.0001$ and Tukey's "day" was $p<0.0001$.

Differences between WT and Adk-tg mice: ${ }^{\#}<<0.05,{ }^{\# \#} p<0.005$, unpaired $t$ test following significant ANOVA interaction "genotype" by repeated "three/four $6 \mathrm{~h}$ intervals" for NREM sleep, REM sleep, and waking ( $p<0.05$ ). The interaction was nonsignificant for REMS during recovery, but factor "genotype" was $p<0.0001$ and Tukey's "genotype" was $p<0.0001$. No differences were found between WT and Adk ${ }^{+\prime-}$ mice.

enings (episodes of waking, <16 s) (Deboer et al., 1994). The time course of SWA $(0.75-4 \mathrm{~Hz})$, spindle frequency activity (SFA) $(10.25-15 \mathrm{~Hz})$, and theta activity $(6.25-9 \mathrm{~Hz})$ for $2 \mathrm{~min}$ before and after the transition from waking or REM sleep to NREM sleep or from NREM sleep to REM sleep was computed as previously (Franken et al., 1994). Data analysis was performed using the MATLAB software package (The MathWorks).

Western blot analysis. We determined protein levels of ADK in brains of $A d k$-tg, $A d k^{+l-}$, and WT mice that had been used for sleep recordings ( $n=6$ mice per genotype). Brain tissue from the right hemispheres was processed for aqueous protein extracts as previously described (Gouder et al., 2004). Cell extracts were resuspended, each containing $40 \mu \mathrm{g}$ proteins, and electrophoresed in a 10\% Tris-glycine gel. After blotting, the membranes were incubated with polyclonal rabbit antiserum against ADK (1:5000) and processed as described previously (Gouder et al., 2004). The membranes were then developed by incubation with peroxidase-conjugated anti-rabbit antibody (7074; 1:8000; Cell Signaling). Immunoblots were quantified using a Kodak Scientific Imaging System (version 3.6.5.k2; Kodak). To normalize ADK immunoreactivity, a mouse monoclonal anti- $\alpha$-tubulin antibody (sc-8035; 1:5000; Santa Cruz) was reprobed on the same blot and the OD ratio of $\mathrm{ADK} / \alpha$-tubulin was calculated.

Statistical analysis. Genotype differences were evaluated by linear mixed model ANOVA, corrected for multiple comparison when appropriate, or by a repeated-measures ANOVA (SAS software; SAS Institute). Post hoc paired and unpaired $t$ test or the Tukey-Kramer, Bonferroni, and Kruskal-Wallis tests were performed if the results of the ANOVA reached statistical significance $(p<0.05)$. All reported values are means over 6-15 mice \pm SEM.

\section{Results}

\section{Overexpression of $A d k$ affects the EEG and impairs sleep regulation}

We previously demonstrated reduced adenosinergic tone in Adk-tg mice (Fedele et al., 2005) that was subsequently validated in several experimental paradigms (Li et al., 2007, 2008a,b; Pignataro et al., 2007; Yee et al., 2007). We therefore hypothesized that this genetic modification would affect sleep.

\section{EEG power spectra}

A statistically significant reduction of EEG power density was observed in the frequencies $<4 \mathrm{~Hz}$ in all vigilance states in $A d k$-tg mice compared with WT mice (Figs. 1, 2). In addition, in REM sleep and waking, EEG power was significantly lower in the Adk-tg mice in the frequencies encompassing the theta band (6.25-11 Hz) (Fig. 1).

\section{Baseline sleep}

Adk-tg mice slept $\sim 60$ min less than WT mice in the dark period (Table 1; Fig. 3, left). The duration of their waking and NREM sleep episodes was significantly longer than in WT mice, whereas their total episode number was lower, indicating more consolidated sleep in Adk-tg mice (Table 2). The relative number of longer NREM sleep episodes ( $>128 \mathrm{~s}$ ) was higher in Adk-tg mice compared with WT mice at the cost of shorter (36-64s) episodes (Fig. 4, left) ( $p<0.005$, Tukey-Kramer test). Sleep fragmentation (defined as the occurrence of waking episodes $<16 \mathrm{~s}$ per hour of sleep) differed between the genotypes (Adk-tg, $20.1 \pm$ 1.3; WT, $24.7 \pm 1.5 ; p=0.039$, unpaired $t$ test $)$.

The amount of REM sleep as well as REM sleep per total sleep time was reduced in Adk-tg mice (Table 1; Fig. 3, left) because of a decreased REM sleep episode frequency (Table 2) ( $p=0.0041$, unpaired $t$ test).

Motor activity data obtained in a separate group of $A d k$-tg and WT mice corroborated the sleep findings. Adk-tg mice spent more time active in the dark period ( $12 \mathrm{~h}$ dark: $328.8 \pm 11.3 \mathrm{vs}$ $268.5 \pm 9.1 \mathrm{~min} ; p=0.0017$, unpaired $t$ test). The intensity of their movements (activity counts per minute) was also significantly higher compared with WT mice (Fig. 4).

In summary, during baseline, sleep and EEG power in frequencies encompassing SWA in NREM sleep and theta activity in waking and REM sleep were reduced in $A d k$-tg mice.

\section{Effects of enhanced sleep pressure by $6 \mathrm{~h}$ SD}

During recovery after SD, Adk-tg and WT mice showed the typical compensatory increase of NREM sleep with a concomitant reduction in waking (Table 1, Fig. 3 ). However, the NREM sleep increase was significantly larger in the $A d k$-tg mice in hours 7-12 (Table 1). The REM sleep rebound was delayed to the second $6 \mathrm{~h}$ recovery interval in all mice (Table 1). Although the baseline 

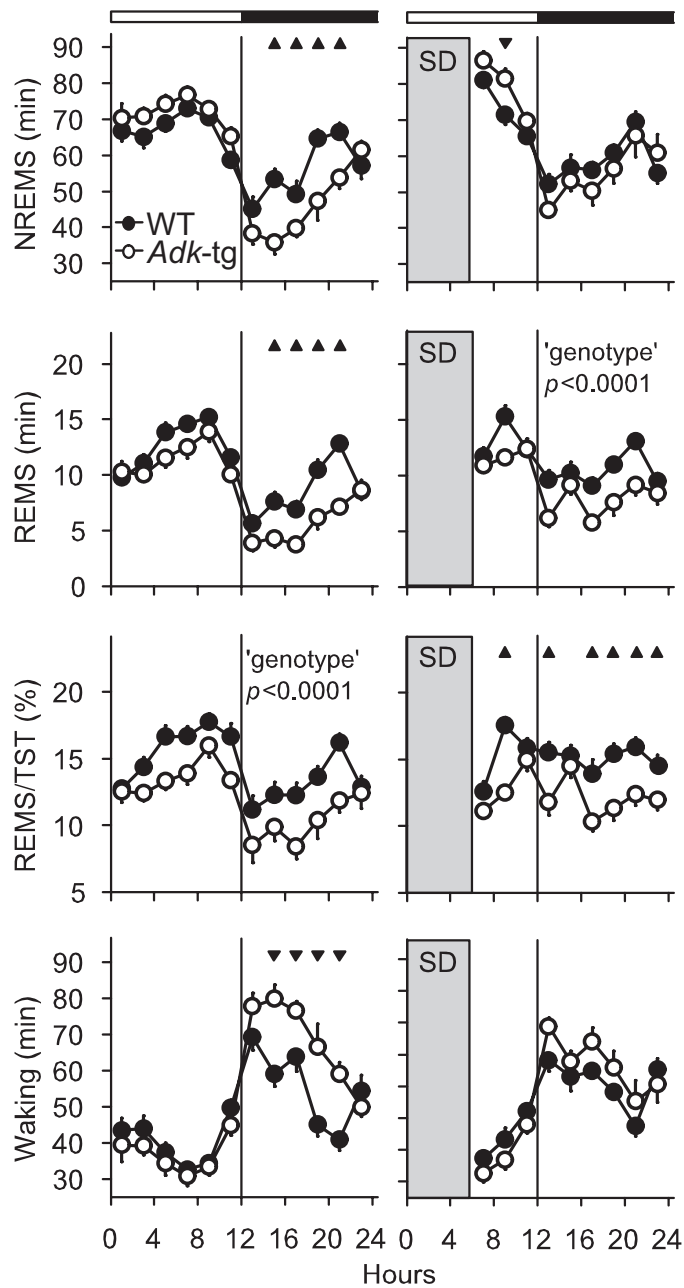

Figure 3. Time course of the vigilance states NREM sleep, REM sleep, waking, and REM sleep as percentage of total sleep time (REMS/TST) in WT and Adk-tg mice during the $24 \mathrm{~h}$ baseline (BL) (left panels) and $18 \mathrm{~h}$ recovery (Rec.) (right panels) after $6 \mathrm{~h} \mathrm{SD}$ (gray area). Shown are mean $2 \mathrm{~h}$ values. Triangles, Genotype differences ( $p<0.05$, unpaired $t$ test; ANOVA "genotype" by repeated " $2 \mathrm{~h}$ interval": NREMS BL, $F_{(11,253)}=5.67, p<0.0001$, and Rec., $F_{(8,184)}=$ $2.14, p=0.034$; REMS BL, $F_{(11,253)}=2.54, p=0.0046$, and Rec., $F_{(8,184)}=1.81, p=0.078$, "genotype" $F_{(1,23)}=26.82, p<0.0001$, followed by Tukey-Kramer "genotype" $p<0.0001$; REMS/TST BL, $F_{(11,253)}=1.14, p=0.33$, "genotype" $F_{(1,23)}=20.96, p=0.0001$ followed by Tukey-Kramer "genotype" $p<0.0001$, and Rec., $F_{(8,184)}=2.04, p=0.0437$; waking BL, $F_{(11,253)}=5.25, p<0.0001$, and Rec., $\left.F_{(8,184)}=1.91, p=0.06\right)$.

genotype differences in REM sleep persisted during recovery (Fig. $3)$, the response to SD was similar in $A d k$-tg and WT mice (recovery-baseline, $6 \mathrm{~h}$ intervals $1-3:-1.9 \pm 1.2 \mathrm{vs}-1.5 \pm 1.1$ $\min , p=0.81 ; 8.9 \pm 1.5$ vs $9.2 \pm 1.4 \mathrm{~min}, p=0.88 ; 1.8 \pm 1.5 \mathrm{vs}$ $3.2 \pm 2.0 \mathrm{~min}, p=0.56$, unpaired $t$ test, in WT vs $A d k$-tg mice, respectively).

\section{SWA and slow wave energy}

We hypothesized that, after SD, mice overexpressing ADK would display a reduced increase in SWA. Accordingly, sleep intensity was significantly lower in $A d k$-tg mice compared with WT mice (Fig. 5A). The magnitude of the typical SD-induced initial increase in SWA was not only lower by $9-12 \%$ in $A d k$-tg mice (first 2 h interval: $p<0.01$, unpaired $t$ test, for PAR and FRO EEG), but SWA remained lower in $A d k$-tg mice throughout the entire recovery period in both EEG derivations (Fig. 5A). Although baseline levels were attained by all mice after $4-6 \mathrm{~h}$ recovery, only $A d k$-tg mice showed a subsequent negative rebound below base- line. The genotype SWA difference in NREM sleep was also evident at the transitions from waking to NREM sleep during the first $6 \mathrm{~h}$ recovery interval (Fig. $5 B$ ). The increase (i.e., buildup) of SWA in Adk-tg mice was significantly lower compared with WT mice immediately after the transitions and remained below the WT increase throughout the 2 min NREM sleep episodes. During the corresponding baseline interval, the dynamics of SWA buildup had been similar in the two genotypes (Fig. 5B). All genotype differences dissipated in the second $6 \mathrm{~h}$ recovery interval.

We computed slow-wave energy (SWE) $(0.75-4 \mathrm{~Hz})$, which takes into account the difference in the amount of NREM sleep between genotypes. Despite the larger amount of NREM sleep, $A d k$-tg mice reached a significantly lower SWE level after $18 \mathrm{~h}$ recovery compared with WT mice in the parietal EEG $(82.1 \pm 1.3$ vs $87.5 \pm 1.8 \% ; p=0.034$, unpaired $t$ test). Significance was not attained in the frontal EEG because of larger interindividual variability $(82.2 \pm 1.9$ vs $87.9 \pm 2.2 \% ; p=0.072)$.

\section{SFA}

Slow waves and spindles are EEG hallmarks of NREM sleep, the latter being most prominent at the transition from NREM sleep to REM sleep (Franken et al., 1994; Vyazovskiy et al., 2004). Spindle density and SWA in NREM sleep show interrelated dynamics in rats and humans (Aeschbach et al., 1997; Vyazovskiy et al., 2004). In addition to the reduced levels of SWA attained by $A d k$-tg mice, the typical surge of SFA immediately before the NREM-REM sleep transitions was significantly reduced in $A d k$-tg mice during baseline (Fig. 6) and recovery (data not shown) compared with WT mice.

Overall, $A d k$-tg mice showed a reduced homeostatic response to enhanced sleep pressure compared with WT mice.

Theta peak frequency in REM sleep was lower in Adk-tg mice Oscillations in the theta frequency range are a distinct feature of REM sleep in rodents (Figs. 1, 2) (Huber et al., 2000). REM sleep EEG spectra were significantly lower in the theta frequency range in Adk-tg mice compared with WT mice. Based on the significant bins in Figure $1(7.25-11 \mathrm{~Hz})$, we investigated whether EEG power would be affected at the transitions from NREM to REM sleep. Adk-tg mice lacked the typical, prominent increase in theta activity after the transitions to REM sleep (Fig. 6). Their theta activity levels were significantly lower than those of WT mice $20 \mathrm{~s}$ before the transitions and remained at a consistently low level after the transitions to REM sleep (the result was similar when the time course of the traditional theta frequency band, $6.25-9 \mathrm{~Hz}$, was computed).

Adenosine is directly linked to energy metabolism in the cell (Scharf et al., 2008) and the peak frequency of theta in REM sleep was affected by a deficiency in energy metabolism (Tafti et al., 2003). We determined the peak frequency within the theta frequency band for individual mice. In $A d k$-tg mice, the peak was at a significantly lower frequency than in WT mice $(7 \pm 0.1 \mathrm{~Hz}$ vs $8 \pm 0.1 \mathrm{~Hz} ; p<0.0001$, unpaired $t$ test $)$.

\section{Effects of $A d k$ overexpression on EEG power during} induced wakefulness

To investigate whether the genotype differences in the response to SD were attributable to behavioral differences during SD, we analyzed the corresponding EEG spectra (Fig. 7). The typical increase in EEG power in the course of SD was observed for a large frequency range $(0.75-8 \mathrm{~Hz})$ in both genotypes and in higher frequencies (13-15 Hz; $p<0.05$, paired $t$ test) in $A d k$-tg mice. The rise rate of EEG power (interval 3 as percentage of interval 1) 
Table 2. Frequency and duration of vigilance state episodes

\begin{tabular}{lllll}
\hline & WT $(n=14)$ & & Adk-tg $(n=11)$ \\
\cline { 2 - 5 } & Frequency & Duration $(\min )$ & Frequency & Duration (min) \\
\hline NREMS & $569.1 \pm 21.3$ & $1.32 \pm 0.06$ & $382.8 \pm 17.1^{* *}$ & $1.88 \pm 0.09^{* *}$ \\
REMS & $123.0 \pm 5.8$ & $1.06 \pm 0.04$ & $96.9 \pm 4.5^{*}$ & $1.06 \pm 0.02$ \\
Waking & $566.2 \pm 20.9$ & $1.03 \pm 0.04$ & $381.9 \pm 17.5^{* *}$ & $1.69 \pm 0.09^{* *}$ \\
\hline
\end{tabular}

Mean frequency and duration of NREM sleep (NREMS), REM sleep (REMS), and waking episodes \pm SEM in WT and Adk-tg mice during the $24 \mathrm{~h}$ baseline.

Genotype differences: ${ }^{*} p<0.005,{ }^{* *} p<0.0005$, unpaired $t$ test.

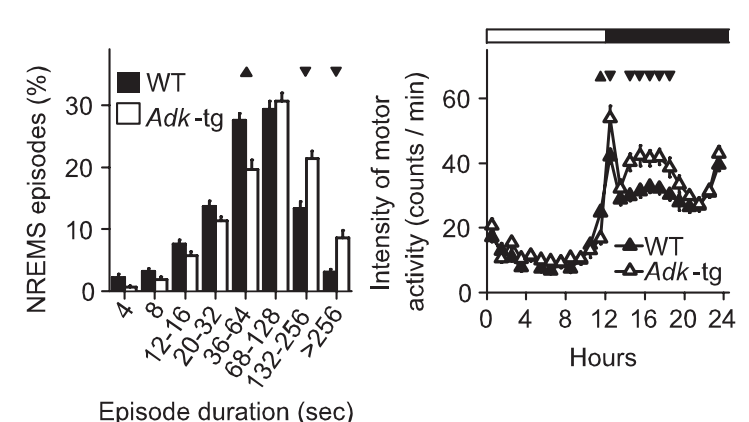

Figure 4. Left, Number of NREM sleep episodes in WT ( $n=14)$ and Adk-tg mice ( $n=11)$ during the $24 \mathrm{~h}$ baseline. Mean values are expressed as percentage of the total number of NREM sleep episodes. Numbers below the $x$-axis are duration range in seconds. Triangles, Genotype differences ( $p<0.005$, Tukey-Kramer; ANOVA "genotype" by "episode duration" $F_{(1,7)}=$ $14.02, p<0.0001$ ). Right, Activity intensity (defined as infrared counts/number of $1 \mathrm{~min}$ epochs with counts $>0$; mean 1 h values; average of 10 consecutive baseline days) in WT ( $n=$ 11 ) and Adk-tg mice $(n=12)$. Triangles, Genotype differences ( $p<0.05$, unpaired $t$ test; ANOVA "genotype" by repeated " $1 \mathrm{~h}$ interval" $\left.F_{(23,483)}=4.32, p<0.0001\right)$.

differed between the two genotypes in frequencies within the SWA band, theta activity, and SFA (Fig. 7). The increase in the 2.25-3.5 Hz band was apparent in all mice (interval 1 vs $3: p<$ $0.0005)$, but the rise rate was significantly lower in the $A d k$-tg mice ( $p=0.0487$, Kruskal-Wallis test). Theta activity was significantly higher in Adk-tg mice than in WT mice throughout SD (rise rate, $p=0.0004$, unpaired $t$ test). SFA increased in the course of SD in $A d k-\operatorname{tg}$ mice only ( $p=0.044$, paired $t$ test) but was significantly lower during the first two $2 \mathrm{~h}$ intervals compared with WT mice (rise rate, $p=0.0455$, unpaired $t$ test).

\section{Reduced expression of $A d k$ has no major effect on sleep}

Our previous data suggest that adenosine metabolism is not significantly altered in $A d k^{+/-}$mice [normal AMP, ADP, ATP, SAM ( $S$-adenosylmethionine), SAH ( $S$-adenosylhomocysteine) levels and normal physiology] (Boison et al., 2002). We therefore hypothesized that sleep would not be altered under conditions of reduced $\mathrm{ADK}$, but normal adenosine metabolites. The amount of sleep (Table 1, Fig. 8), as well as the average duration and frequency of vigilance state episodes (data not shown), did not differ between $A d k^{+/-}$and WT mice. Moreover, the $24 \mathrm{~h}$ baseline time course of SWA in NREM sleep was similar in the two genotypes (Fig. 8). When sleep pressure was enhanced by SD, the typical increase in NREM sleep, REM sleep, and SWA in NREM sleep was evident, but none of these variables differed significantly between $A d k^{+/-}$and WT mice (Table 1). We conclude that the changes in $\mathrm{ADK}$ expression per se in the absence of any changes in adenosine metabolites do not affect sleep.

\section{ADK protein expression level}

To validate our findings, we retrospectively quantified ADK protein expression levels in brain extracts from representative experimental animals of each genotype after the conclusion of the
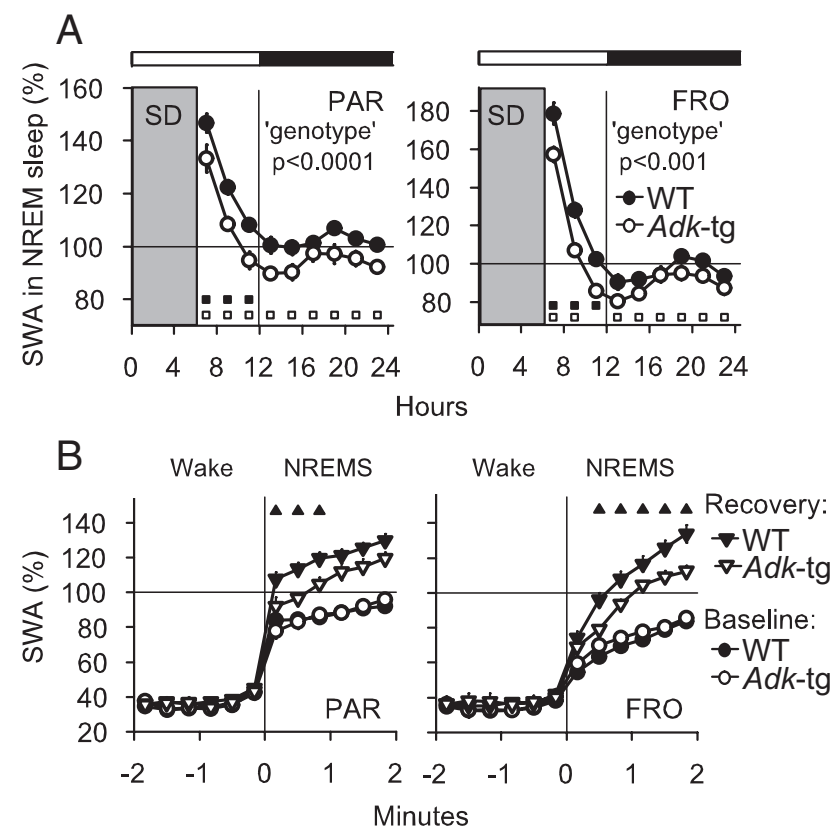

Figure 5. $\quad A$, Time course of SWA in NREM sleep in the parietal (PAR) and frontal (FRO) EEG in WT and $A d k$-tg mice during $18 \mathrm{~h}$ recovery after $6 \mathrm{hSD}$ (gray area). Mean $2 \mathrm{~h}$ values are expressed as percentage of the mean $24 \mathrm{~h}$ baseline SWA in NREM sleep of the corresponding EEG. Genotype differences ( $p<0.001$, Tukey-Kramer; ANOVA "genotype" $F_{(1,24)}=29.04, p<0.0001$ for PAR, and $F_{(1,24)}=14.23, p<0.0009$ for FRO; interaction "genotype" by "2 $\mathrm{h}$ interval" $F_{(8,183)}=1.06, p=0.39$ for PAR, and $F_{(8,183)}=1.55, p=0.14$ for FRO). Differences from corresponding baseline interval in $A d k$-tg (open squares below the curves; $p<0.05$, paired $t$ test; ANOVA "condition" by " $2 \mathrm{~h}$ interval" $F_{(8,180)}=32.81$ and $46.08, p<0.0001$ for PAR and FR0, respectively) and WT mice (filled squares; $p<0.0001$, paired $t$ test; $F_{(8,234)}=48.32$ and $46.76, p<0.0001$ for PAR and FRO). $B$, Time course of SWA during the 2 min before and after transitions from waking to NREM sleep. Mean 20 s values computed for the first $6 \mathrm{~h}$ interval after SD and the corresponding baseline interval are expressed as percentage of the mean $24 \mathrm{~h}$ baseline SWA in NREM sleep. Triangles, Genotype differences during recovery $(p<0.05$, unpaired $t$ test; ANOVA "genotype" by "20 s epoch": $F_{(11,252)}=2.01, p=0.0276$ for PAR, and $F_{(11,252)}=2.73, p=0.0024$ for FRO).

experiments ( $n=6$ per genotype). Adk-tg mutants expressed significantly higher ADK levels in the brain (142\% vs WT mice; $p<0.001$, unpaired $t$ test) of the short ADK isoform (Fig. 9), whereas ADK expression levels of the short and long ADK isoforms in $A d k^{+/-}$mice were significantly lower (65\% of WT mice; $p<0.001$, unpaired $t$ test).

\section{Discussion}

Adenosine levels in adult brain are primarily regulated by an astrocyte-based adenosine cycle (Boison, 2008). Astrocytes can release adenosine precursor ATP either by vesicular transport (Pascual et al., 2005) or via hemichannels (Kang et al., 2008). Once outside the cell, ATP is rapidly degraded by a cascade of ectonucleotidases (Zimmermann, 2000). In contrast to conventional neurotransmitters, there is no regulated transportermediated reuptake system for adenosine. On the contrary, 
astrocytes express two types of equilibrative nucleoside transporters (Baldwin et al., 2004). Inside the cell, adenosine is removed by phosphorylation into AMP by ADK. Thus, ADK drives the influx of adenosine into the astrocytes and regulates the abundance of extracellular adenosine.

\section{Role of ADK in sleep homeostasis}

In this study, we show for the first time that increasing ADK, the key enzyme controlling adenosine levels, robustly altered vigilance states and specific EEG oscillations that are the hallmarks of NREM sleep, REM sleep, and wakefulness. In particular, the increases in brain ADK protein and ADK activity in Adk-tg mice resulted in a remarkable reduction of EEG power below $4 \mathrm{~Hz}$ and in the theta frequency range (Fig. 1), pointing to a deficiency in mechanisms generating EEG slow waves and theta oscillations. Moreover, ADK overexpression led to a reduction of sleep, which was partially compensated for by an increase in sleep consolidation. Under enhanced sleep pressure, a deficiency in the homeostatic regulation of sleep became apparent in $A d k$-tg mice. The increase of SWA in NREM sleep and its buildup at the waking-NREM sleep transitions were lower in Adk-tg mice (Fig. 5), indicating a reduced capacity to intensify sleep. This finding is remarkable since $A d k$-tg mice had slept less than WT mice during the dark period preceding SD. Therefore, they were under higher sleep pressure at the beginning of $\mathrm{SD}$. The deficiency in sleep regulatory mechanisms was further demonstrated by the lower SWE accumulated after $18 \mathrm{~h}$ recovery in Adk-tg mice.

ADK is highly conserved in evolution and ubiquitously expressed (Boison, 2006). Its importance for survival is emphasized by the lethality of the disruption of the Adk gene (Boison et al., 2002). Two different isoforms of ADK exist (Cui et al., 2009), a cytoplasmic isoform thought to regulate ambient levels of adenosine, whereas a nuclear isoform might be implicated in epigenetic mechanisms. This dual functionality of the enzyme has been postulated previously (Studer et al., 2006). Heterozygous Adk mice have no obvious phenotype (Boison et al., 2002), which we here confirmed for sleep and sleep regulation. We reported previously that $A d k^{+/-}$mice display alterations in ADK expression in the absence of changes in adenosine metabolism. These findings suggest that the nuclear isoform of ADK is likely not involved in sleep regulation. In line with this notion, $A d k$-tg mice that selectively overexpress the cytoplasmic isoform of ADK, but lack the nuclear isoform of ADK, show a profound sleep phenotype. Together, these data suggest that the cytoplasmic, but not the nuclear isoform of $\mathrm{ADK}$ is involved in sleep regulation.

Sleep deprivation enhanced extracellular adenosine, which thereafter decreased during recovery sleep (Porkka-Heiskanen et al., 1997, 2000; Basheer et al., 2004). Benington and Heller (1995) proposed that adenosine continues to be released during recovery from $\mathrm{SD}$ as a product of a putative restorative process occurring during sleep. The astrocytic and neuronal ADK overexpression in $A d k$-tg mice should lead to a faster adenosine clearance from the extracellular space resulting in a slower accumulation of sleep need during prolonged wakefulness, and in a reduced response to SD. Thus, we had hypothesized that the overall reduction in brain adenosine levels in Adk-tg mice might not only modify sleep under base-
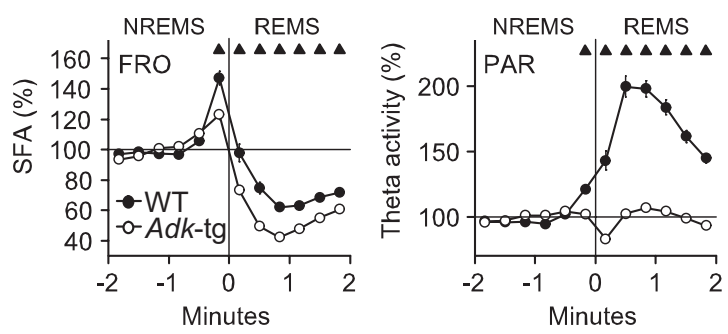

Figure 6. Time course of specific frequency bands during the $2 \mathrm{~min}$ before and after transitions from NREM to REM sleep in WT and Adk-tg mice. SFA (10.25-15 Hz) in the frontal EEG (left panel) and theta frequency activity $(7.25-11 \mathrm{~Hz})$ in the parietal EEG (right panel). Mean $20 \mathrm{~s}$ values for the $24 \mathrm{~h}$ baseline are expressed as percentage of the mean $24 \mathrm{~h}$ baseline SFA or theta activity in NREM sleep. Triangles, Genotype differences (SFA, $p<0.0005$, unpaired $t$ test; ANOVA "genotype" by "20 s epoch": $F_{(11,252)}=10.64$ and $41.49, p<0.0001$ for SFA and theta activity, respectively).

$5 \mathrm{~Hz} \quad 6.25-9 \mathrm{~Hz}$

$11.25-15 \mathrm{~Hz}$
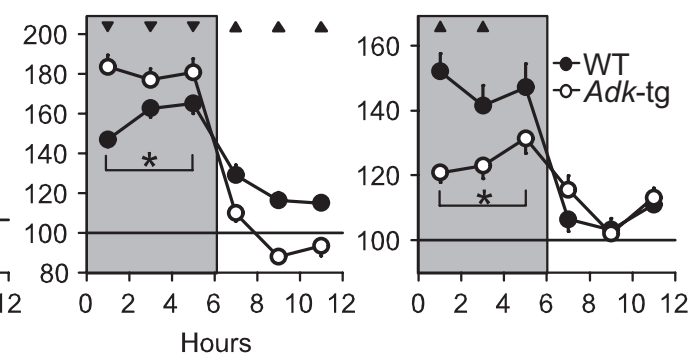

Figure 7. Time course of EEG power in waking in three frequency bands in the parietal EEG of WT and $A d k$-tg mice during the $6 \mathrm{~h}$ corresponding frequency band in waking. Triangles, Genotype differences $(p<0.05$, unpaired $t$ test; ANOVA "genotype" by " $2 \mathrm{~h}$ interval" $F_{(5,114)}=2.46, p=0.037$, for $2.25-3.5 \mathrm{~Hz}$ band, $F_{(5,114)}=15.67$ and $6.95, p<0.0001$, for $6.25-9$ and $11.25-15 \mathrm{~Hz}$ band, respectively). Asterisks, Difference between the first and last $2 \mathrm{hSD}$ interval ( $p<0.05$, paired $t$ test).
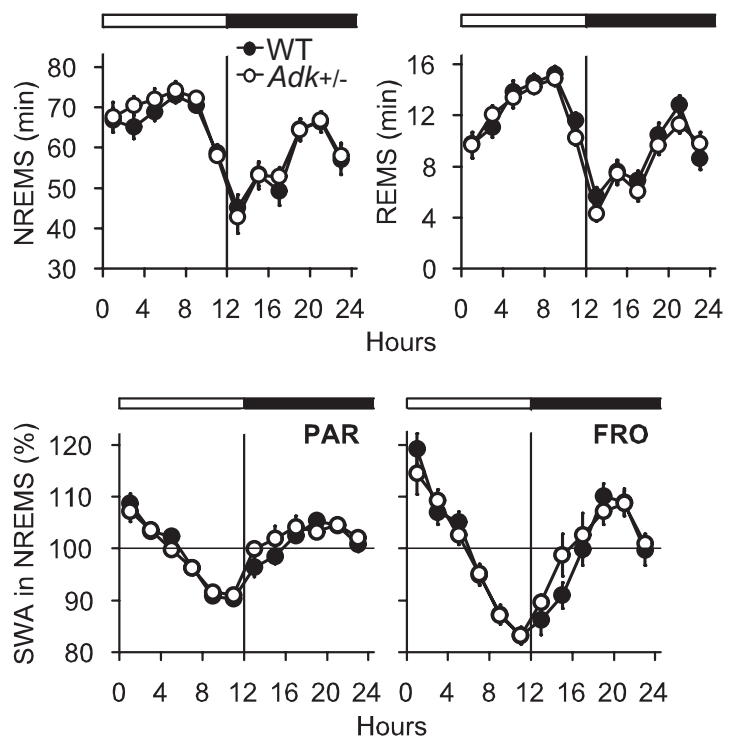

Figure 8. Time course of NREM sleep (NREMS), REM sleep (REMS), and SWA (EEG power between 0.75 and $4 \mathrm{~Hz}$ ) in NREM sleep in the parietal (PAR) and frontal (FRO) EEG in WT (black dots; $n=14$ ) and $A d k^{+/-}$mice (white dots; $n=15$ ) during the $24 \mathrm{~h}$ baseline. The white and black bars indicate the $12 \mathrm{~h}$ light and dark period. Data represent $2 \mathrm{~h}$ means; SWA is expressed as percentage of the $24 \mathrm{~h}$ mean SWA in NREM sleep.

line conditions but also attenuate the rise in sleep pressure during $\mathrm{SD}$, and impair sleep restorative processes during recovery.

The deficiency in the Adk-tg mice was not restricted to EEG slow waves but also comprised spindle activity in NREM sleep 

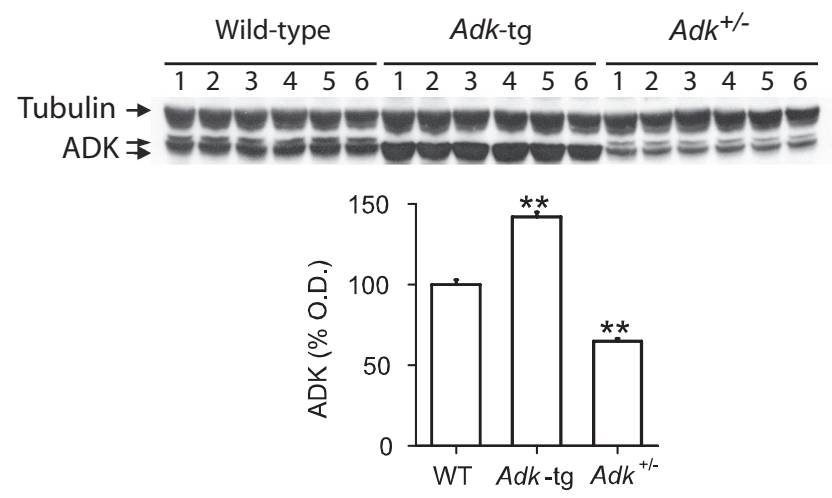

Figure 9. Top, Western blot of ADK protein levels from the right hemisphere of adult WT, $A d k^{+I-}$, and Adk-tg mice (numbers 1-6 correspond to individual mice). Bottom, Corresponding quantitative analysis of the ADK levels of $n=6$ mice per genotype (0.D., optical density). ADK was first normalized to equal loading according to the $\alpha$-tubulin standard and then to the ADK level of WT mice $(=100 \%)$. Differences from WT: ${ }^{* *} p<0.001$, unpaired $t$ test.

and theta activity in waking and REM sleep. Spindle and slowwave oscillations originate in the thalamocortical network and depend on the hyperpolarization of thalamocortical neurons (Steriade et al., 1993). Notably, Adk-tg mice showed both reduced SWA levels in NREM sleep and a 24\% lower surge of SFA at NREM-REM sleep transitions compared with WT mice (Fig. 6). During SD-induced wakefulness, Adk-tg mice showed a larger increase of SFA and a smaller increase of SWA (Fig. 7). Adenosine $A_{1}$ receptors, which are predominantly expressed in the cortex and in several thalamic nuclei, including the thalamic reticular nucleus (Rosin et al., 1998; Ochiishi et al., 1999), may mediate these genotype differences. Robust, but opposing, presynaptic and postsynaptic effects of adenosine via $A_{1}$ receptors on thalamocortical oscillations were reported in ex vivo thalamic slices (Pape, 1992; Ulrich and Huguenard, 1995; Fontanez and Porter, 2006). Our results are in agreement with a potent role of adenosine in mediating the hyperpolarization of thalamocortical neurons, which de-inactivates the low-threshold calcium channels in thalamic relay nuclei underlying the occurrence of slow waves (for review, see McCormick, 1992). The reduced adenosinergic tone in Adk-tg mice (Fedele et al., 2005) may also alter ATP-regulated phosphorylation of T-type $\mathrm{Ca}^{2+}$ channels (Leresche et al., 2004). In addition, adenosine modulates the release of several neurotransmitters (Fredholm et al., 2005), including cholinergic, monoaminergic, and histaminergic inputs to the thalamocortical network, which, thereby, may alter the firing pattern of thalamocortical neurons.

\section{The waking EEG is affected by Adk overexpression}

Both the amount and quality of wakefulness were affected by ADK overexpression (Table 1). Adk-tg mice were more active during their waking bouts compared with WT mice (Fig. 4), confirming previous results (Fedele et al., 2005; Yee et al., 2007). These findings mimic the stimulant properties of the adenosine receptor antagonist caffeine (Schwierin et al., 1996; Fredholm et al., 2005; Huang et al., 2005). It is likely that the increase in wakefulness and corresponding reduction in sleep in $A d k$-tg mice is a consequence of reduced adenosinergic tone throughout the brain, leading to increased activity of the ascending monoaminergic system on the thalamus.

It is well established from human and animal studies that EEG power in the low frequencies increases in the course of prolonged wakefulness (Torsvall and Akerstedt, 1987; Franken et al., 1993;
Cajochen et al., 1995; Aeschbach et al., 1999; Achermann and Borbély, 2003; Vyazovskiy and Tobler, 2005). We found a robust increase in EEG power of frequencies $<8 \mathrm{~Hz}$ in both genotypes in the course of SD. Interestingly, initial levels and rise rates of power in specific frequencies were different in Adk-tg mice (Fig. 7 ). These differences may result from the behavioral alterations mentioned above. The mechanisms underlying these alterations remain unclear.

\section{Role of Adk in REM sleep}

Strikingly, Adk-tg mice showed an overall reduction of REM sleep (Table 1). Several lines of evidence support a role of the adenosinergic system in the onset and maintenance of REM sleep. Microinjections of the $\mathrm{A}_{1}$ receptor agonist cyclopentyladenosine in the pontine reticular formation, a region implicated in the modulation of REM sleep (Monti and Monti, 2000), enhanced REM sleep duration in rats (Marks and Birabil, 2000; Marks et al., 2003). This effect was counteracted by pretreatment with the adenosine receptor antagonist cyclopentyltheophylline (Marks and Birabil, 1998). Consistently, microinjections of an $\mathrm{A}_{2 \mathrm{~A}}$ receptor agonist in the same region also enhanced REM sleep and increased acetylcholine release in rodents (Marks et al., 2003; Coleman et al., 2006). Initiation of REM sleep may be deficient in $A d k$-tg mice because of alterations in glutamatergic excitation and GABAergic inhibition of REM sleep active neurons in the sublaterodorsal nucleus (Luppi et al., 2006). Once REM sleep is initiated, it is maintained normally as indicated by the similar duration of REM sleep episodes in WT and $A d k$-tg mice. Under increased sleep pressure, the REM sleep rebound was similar in the two genotypes, indicating that basic REM sleep regulatory mechanisms are intact in Adk-tg mice.

In the present study, reduced theta activity after transitions to REM sleep in Adk-tg mice implicates a role for adenosine in the modulation of theta oscillations. Moreover, theta peak frequency in REM sleep was significantly lower in Adk-tg mice compared with WT mice, whereas waking theta peak frequency was similar in the two genotypes ( $p=0.18$, unpaired $t$ test). Changes in adenosinergic tone because of ADK overexpression may modulate the frequency and amplitude of theta oscillations during REM sleep by changing the excitatory input from the brainstem reticular formation to the septum (Vinogradova, 1995).

\section{Conclusions}

Our data suggest that ADK overexpression profoundly alters the sleep phenotype, likely by lowering adenosine tone in the brain. It is tempting to speculate that ADK, by controlling adenosine levels and its receptor-mediated effects, may tune and integrate other neurotransmitter pathways involved in sleep-wake regulation and the generation of related EEG oscillations. Overall, our results are in accordance with a global rather than a regionspecific role of adenosine in sleep regulation (Heller, 2006).

\section{References}

Achermann P, Borbély AA (2003) Mathematical models of sleep regulation. Front Biosci 8:s683-s693.

Aeschbach D, Dijk DJ, Borbély AA (1997) Dynamics of EEG spindle frequency activity during extended sleep in humans: relationship to slowwave activity and time of day. Brain Res 748:131-136.

Aeschbach D, Matthews JR, Postolache TT, Jackson MA, Giesen HA, Wehr TA (1999) Two circadian rhythms in the human electroencephalogram during wakefulness. Am J Physiol 277:R1771-R1779.

Alanko L, Heiskanen S, Stenberg D, Porkka-Heiskanen T (2003) Adenosine kinase and $5^{\prime}$-nucleotidase activity after prolonged wakefulness in the cortex and the basal forebrain of rat. Neurochem Int 42:449-454. 
Alanko LO, Laitinen JT, Stenberg D, Porkka-Heiskanen T (2004) Adenosine A1 receptor-dependent G-protein activity in the rat brain during prolonged wakefulness. Neuroreport 15:2133-2137.

Baldwin SA, Beal PR, Yao SY, King AE, Cass CE, Young JD (2004) The equilibrative nucleoside transporter family, SLC29. Pflugers Arch 447: 735-743.

Basheer R, Halldner L, Alanko L, McCarley RW, Fredholm BB, PorkkaHeiskanen T (2001) Opposite changes in adenosine A1 and A2A receptor mRNA in the rat following sleep deprivation. Neuroreport 12: $1577-1580$.

Basheer R, Strecker RE, Thakkar MM, McCarley RW (2004) Adenosine and sleep-wake regulation. Prog Neurobiol 73:379-396.

Benington JH, Heller HC (1995) Restoration of brain energy metabolism as the function of sleep. Prog Neurobiol 45:347-360.

Benington JH, Kodali SK, Heller HC (1995) Stimulation of Al adenosine receptors mimics the electroencephalographic effects of sleep deprivation. Brain Res 692:79-85.

Biaggioni I, Paul S, Puckett A, Arzubiaga C (1991) Caffeine and theophylline as adenosine receptor antagonists in humans. J Pharmacol Exp Ther 258:588-593.

Bjorness TE, Kelly CL, Gao T, Poffenberger V, Greene RW (2009) Control and function of the homeostatic sleep response by adenosine $\mathrm{A}_{1}$ receptors. J Neurosci 29:1267-1276.

Boison D (2006) Adenosine kinase, epilepsy and stroke: mechanisms and therapies. Trends Pharmacol Sci 27:652-658.

Boison D (2008) Adenosine as a neuromodulator in neurological diseases. Curr Opin Pharmacol 8:2-7.

Boison D, Scheurer L, Zumsteg V, Rülicke T, Litynski P, Fowler B, Brandner S, Mohler H (2002) Neonatal hepatic steatosis by disruption of the adenosine kinase gene. Proc Natl Acad Sci U S A 99:6985-6990.

Cajochen C, Brunner DP, Kräuchi K, Graw P, Wirz-Justice A (1995) Power density in theta/alpha frequencies of the waking EEG progressively increases during sustained wakefulness. Sleep 18:890-894.

Chagoya de Sánchez V, Hernández Múñoz R, Suárez J, Vidrio S, Yáñez L, Díaz Múñoz M (1993) Day-night variations of adenosine and its metabolizing enzymes in the brain cortex of the rat-possible physiological significance for the energetic homeostasis and the sleep-wake cycle. Brain Res 612:115-121.

Coleman CG, Baghdoyan HA, Lydic R (2006) Dialysis delivery of an adenosine A2A agonist into the pontine reticular formation of C57BL/6 J mouse increases pontine acetylcholine release and sleep. J Neurochem 96:1750-1759.

Cui XA, Singh B, Park J, Gupta RS (2009) Subcellular localization of adenosine kinase in mammalian cells: the long isoform of $\mathrm{AdK}$ is localized in the nucleus. Biochem Biophys Res Commun 388:46-50.

Datta S, Maclean RR (2007) Neurobiological mechanisms for the regulation of mammalian sleep-wake behavior: reinterpretation of historical evidence and inclusion of contemporary cellular and molecular evidence. Neurosci Biobehav Rev 31:775-824.

Deboer T, Franken P, Tobler I (1994) Sleep and cortical temperature in the Djungarian hamster under baseline conditions and after sleep deprivation. J Comp Physiol A 174:145-155.

Fedele DE, Gouder N, Güttinger M, Gabernet L, Scheurer L, Rülicke T, Crestani F, Boison D (2005) Astrogliosis in epilepsy leads to overexpression of adenosine kinase, resulting in seizure aggravation. Brain 128:2383-2395.

Fontanez DE, Porter JT (2006) Adenosine Al receptors decrease thalamic excitation of inhibitory and excitatory neurons in the barrel cortex. Neuroscience 137:1177-1184.

Franken P, Tobler I, Borbély AA (1993) Effects of 12-h sleep deprivation and of 12-h cold exposure on sleep regulation and cortical temperature in the rat. Physiol Behav 54:885-894.

Franken P, Dijk DJ, Tobler I, Borbély AA (1994) High-frequency components of the rat electrocorticogram are modulated by the vigilance states. Neurosci Lett 167:89-92.

Fredholm BB, Chen JF, Masino SA, Vaugeois JM (2005) Actions of adenosine at its receptors in the CNS: insights from knockouts and drugs. Annu Rev Pharmacol Toxicol 45:385-412.

Gallopin T, Luppi PH, Cauli B, Urade Y, Rossier J, Hayaishi O, Lambolez B, Fort $\mathrm{P}$ (2005) The endogenous somnogen adenosine excites a subset of sleep-promoting neurons via A2A receptors in the ventrolateral preoptic nucleus. Neuroscience 134:1377-1390.
Gouder N, Scheurer L, Fritschy JM, Boison D (2004) Overexpression of adenosine kinase in epileptic hippocampus contributes to epileptogenesis. J Neurosci 24:692-701.

Halassa MM, Florian C, Fellin T, Munoz JR, Lee SY, Abel T, Haydon PG, Frank MG (2009) Astrocytic modulation of sleep homeostasis and cognitive consequences of sleep loss. Neuron 61:213-219.

Haulică I, Ababei L, Brănisteanu D, Topoliceanu F (1973) Letter: preliminary data on the possible hypnogenic role of adenosine. J Neurochem 21:1019-1020.

Hayaishi O, Urade Y, Eguchi N, Huang ZL (2004) Genes for prostaglandin $\mathrm{D}$ synthase and receptor as well as adenosine $\mathrm{A} 2 \mathrm{~A}$ receptor are involved in the homeostatic regulation of NREM sleep. Arch Ital Biol 142:533-539.

Heller HC (2006) A global rather than local role for adenosine in sleep homeostasis. Sleep 29:1382-1383; discussion 1387-1389.

Huang ZL, Qu WM, Eguchi N, Chen JF, Schwarzschild MA, Fredholm BB, Urade Y, Hayaishi O (2005) Adenosine A2A, but not A1, receptors mediate the arousal effect of caffeine. Nat Neurosci 8:858-859.

Huang ZL, Urade Y, Hayaishi O (2007) Prostaglandins and adenosine in the regulation of sleep and wakefulness. Curr Opin Pharmacol 7:33-38.

Huber A, Padrun V, Déglon N, Aebischer P, Möhler H, Boison D (2001) Grafts of adenosine-releasing cells suppress seizures in kindling epilepsy. Proc Natl Acad Sci U S A 98:7611-7616.

Huber R, Deboer T, Tobler I (2000) Topography of EEG dynamics after sleep deprivation in mice. J Neurophysiol 84:1888-1893.

Kang J, Kang N, Lovatt D, Torres A, Zhao Z, Lin J, Nedergaard M (2008) Connexin 43 hemichannels are permeable to ATP. J Neurosci 28:47024711.

Landolt HP, Werth E, Borbély AA, Dijk DJ (1995) Caffeine intake (200 mg) in the morning affects human sleep and EEG power spectra at night. Brain Res 675:67-74.

Leresche N, Hering J, Lambert RC (2004) Paradoxical potentiation of neuronal T-type $\mathrm{Ca}^{2+}$ current by ATP at resting membrane potential. J Neurosci 24:5592-5602.

Li T, Quan Lan J, Fredholm BB, Simon RP, Boison D (2007) Adenosine dysfunction in astrogliosis: cause for seizure generation? Neuron Glia Biol 3:353-366.

Li T, Ren G, Lusardi T, Wilz A, Lan JQ, Iwasato T, Itohara S, Simon RP, Boison D (2008a) Adenosine kinase is a target for the prediction and prevention of epileptogenesis in mice. J Clin Invest 118:571-582.

Li T, Lan JQ, Boison D (2008b) Uncoupling of astrogliosis from epileptogenesis in adenosine kinase (ADK) transgenic mice. Neuron Glia Biol 4:91-99.

Lloyd HG, Fredholm BB (1995) Involvement of adenosine deaminase and adenosine kinase in regulating extracellular adenosine concentration in rat hippocampal slices. Neurochem Int 26:387-395.

Luppi PH, Gervasoni D, Verret L, Goutagny R, Peyron C, Salvert D, Leger L, Fort P (2006) Paradoxical (REM) sleep genesis: the switch from an aminergic-cholinergic to a GABAergic-glutamatergic hypothesis. J Physiol Paris 100:271-283.

Mackiewicz M, Nikonova EV, Zimmerman JE, Galante RJ, Zhang L, Cater JR, Geiger JD, Pack AI (2003) Enzymes of adenosine metabolism in the brain: diurnal rhythm and the effect of sleep deprivation. J Neurochem 85:348-357.

Marks GA, Birabil CG (1998) Enhancement of rapid eye movement sleep in the rat by cholinergic and adenosinergic agonists infused into the pontine reticular formation. Neuroscience 86:29-37.

Marks GA, Birabil CG (2000) Infusion of adenylyl cyclase inhibitor SQ22,536 into the medial pontine reticular formation of rats enhances rapid eye movement sleep. Neuroscience 98:311-315.

Marks GA, Shaffery JP, Speciale SG, Birabil CG (2003) Enhancement of rapid eye movement sleep in the rat by actions at $\mathrm{A} 1$ and $\mathrm{A} 2 \mathrm{a}$ adenosine receptor subtypes with a differential sensitivity to atropine. Neuroscience 116:913-920.

Marley E, Nistico G (1972) Effects of catecholamines and adenosine derivatives given into the brain of fowls. Br J Pharmacol 46:619-636.

Martin JV, Berman KF, Skolnick P, Mendelson WB (1989) Behavioral and electroencephalographic effects of the adenosine1 agonist, L-PIA. Pharmacol Biochem Behav 34:507-510.

Mathews II, Erion MD, Ealick SE (1998) Structure of human adenosine kinase at 1.5 A resolution. Biochemistry 37:15607-15620.

McCormick DA (1992) Neurotransmitter actions in the thalamus and cere- 
bral cortex and their role in neuromodulation of thalamocortical activity. Prog Neurobiol 39:337-388.

Methippara MM, Kumar S, Alam MN, Szymusiak R, McGinty D (2005) Effects on sleep of microdialysis of adenosine $\mathrm{A} 1$ and $\mathrm{A} 2 \mathrm{a}$ receptor analogs into the lateral preoptic area of rats. Am J Physiol Regul Integr Comp Physiol 289:R1715-R1723.

Monti JM, Monti D (2000) Role of dorsal raphe nucleus serotonin 5-HT1A receptor in the regulation of REM sleep. Life Sci 66:1999-2012.

Ochiishi T, Chen L, Yukawa A, Saitoh Y, Sekino Y, Arai T, Nakata H, Miyamoto H (1999) Cellular localization of adenosine Al receptors in rat forebrain: immunohistochemical analysis using adenosine $\mathrm{Al}$ receptor-specific monoclonal antibody. J Comp Neurol 411:301-316.

Oishi Y, Huang ZL, Fredholm BB, Urade Y, Hayaishi O (2008) Adenosine in the tuberomammillary nucleus inhibits the histaminergic system via A1 receptors and promotes non-rapid eye movement sleep. Proc Natl Acad Sci U S A 105:19992-19997.

Pak MA, Haas HL, Decking UK, Schrader J (1994) Inhibition of adenosine kinase increases endogenous adenosine and depresses neuronal activity in hippocampal slices. Neuropharmacology 33:1049-1053.

Pape HC (1992) Adenosine promotes burst activity in guinea-pig geniculocortical neurones through two different ionic mechanisms. J Physiol 447:729-753.

Pascual O, Casper KB, Kubera C, Zhang J, Revilla-Sanchez R, Sul JY, Takano H, Moss SJ, McCarthy K, Haydon PG (2005) Astrocytic purinergic signaling coordinates synaptic networks. Science 310:113-116.

Pignataro G, Simon RP, Boison D (2007) Transgenic overexpression of adenosine kinase aggravates cell death in ischemia. J Cereb Blood Flow Metab 27:1-5.

Porkka-Heiskanen T, Strecker RE, Thakkar M, Bjorkum AA, Greene RW, McCarley RW (1997) Adenosine: a mediator of the sleep-inducing effects of prolonged wakefulness. Science 276:1265-1268.

Porkka-Heiskanen T, Strecker RE, McCarley RW (2000) Brain sitespecificity of extracellular adenosine concentration changes during sleep deprivation and spontaneous sleep: an in vivo microdialysis study. Neuroscience 99:507-517.

Portas CM, Thakkar M, Rainnie DG, Greene RW, McCarley RW (1997) Role of adenosine in behavioral state modulation: a microdialysis study in the freely moving cat. Neuroscience 79:225-235.

Radulovacki M (1985) Role of adenosine in sleep in rats. Rev Clin Basic Pharm 5:327-339.

Radulovacki M, Virus RM, Rapoza D, Crane RA (1985) A comparison of the dose response effects of pyrimidine ribonucleosides and adenosine on sleep in rats. Psychopharmacology (Berl) 87:136-140.

Rosin DL, Robeva A, Woodard RL, Guyenet PG, Linden J (1998) Immunohistochemical localization of adenosine A2A receptors in the rat central nervous system. J Comp Neurol 401:163-186.

Sarda N, Gharib A, Coindet J, Pacheco H, Jouvet M (1986) Possible involvement of the $S$-adenosyl-L-homocysteine metabolites, adenosine and L-homocysteine, in sleep in rats. Neurosci Lett 66:287-292.

Satoh S, Matsumura H, Hayaishi O (1998) Involvement of adenosine A2A receptor in sleep promotion. Eur J Pharmacol 351:155-162.

Satoh S, Matsumura H, Koike N, Tokunaga Y, Maeda T, Hayaishi O (1999) Region-dependent difference in the sleep-promoting potency of an adenosine A2A receptor agonist. Eur J Neurosci 11:1587-1597.

Scammell TE, Gerashchenko DY, Mochizuki T, McCarthy MT, Estabrooke IV, Sears CA, Saper CB, Urade Y, Hayaishi O (2001) An adenosine A2a agonist increases sleep and induces Fos in ventrolateral preoptic neurons. Neuroscience 107:653-663.
Scharf MT, Naidoo N, Zimmerman JE, Pack AI (2008) The energy hypothesis of sleep revisited. Prog Neurobiol 86:264-280.

Schwierin B, Borbély AA, Tobler I (1996) Effects of N6-cyclopentyladenosine and caffeine on sleep regulation in the rat. Eur J Pharmacol 300:163-171.

Snyder SH, Katims JJ, Annau Z, Bruns RF, Daly JW (1981) Adenosine receptors and behavioral actions of methylxanthines. Proc Natl Acad Sci U S A 78:3260-3264.

Steriade M, McCormick DA, Sejnowski TJ (1993) Thalamocortical oscillations in the sleeping and aroused brain. Science 262:679-685.

Strecker RE, Morairty S, Thakkar MM, Porkka-Heiskanen T, Basheer R, Dauphin LJ, Rainnie DG, Portas CM, Greene RW, McCarley RW (2000) Adenosinergic modulation of basal forebrain and preoptic/anterior hypothalamic neuronal activity in the control of behavioral state. Behav Brain Res 115:183-204.

Studer FE, Fedele DE, Marowsky A, Schwerdel C, Wernli K, Vogt K, Fritschy JM, Boison D (2006) Shift of adenosine kinase expression from neurons to astrocytes during postnatal development suggests dual functionality of the enzyme. Neuroscience 142:125-137.

Tafti M, Petit B, Chollet D, Neidhart E, de Bilbao F, Kiss JZ, Wood PA, Franken P (2003) Deficiency in short-chain fatty acid beta-oxidation affects theta oscillations during sleep. Nat Genet 34:320-325.

Thakkar MM, Winston S, McCarley RW (2003) A $A_{1}$ receptor and adenosinergic homeostatic regulation of sleep-wakefulness: effects of antisense to the $\mathrm{A}_{1}$ receptor in the cholinergic basal forebrain. J Neurosci 23:42784287.

Ticho SR, Radulovacki M (1991) Role of adenosine in sleep and temperature regulation in the preoptic area of rats. Pharmacol Biochem Behav 40:33-40.

Tobler I, Deboer T, Fischer M (1997) Sleep and sleep regulation in normal and prion protein-deficient mice. J Neurosci 17:1869-1879.

Torsvall L, Akerstedt T (1987) Sleepiness on the job: continuously measured EEG changes in train drivers. Electroencephalogr Clin Neurophysiol 66:502-511.

Ulrich D, Huguenard JR (1995) Purinergic inhibition of GABA and glutamate release in the thalamus: implications for thalamic network activity. Neuron 15:909-918.

Vinogradova OS (1995) Expression, control, and probable functional significance of the neuronal theta-rhythm. Prog Neurobiol 45:523-583.

Virus RM, Djuricic-Nedelson M, Radulovacki M, Green RD (1983) The effects of adenosine and $2^{\prime}$-deoxycoformycin on sleep and wakefulness in rats. Neuropharmacology 22:1401-1404

Vyazovskiy VV, Tobler I (2005) Theta activity in the waking EEG is a marker of sleep propensity in the rat. Brain Res 1050:64-71.

Vyazovskiy VV, Achermann P, Borbély AA, Tobler I (2004) The dynamics of spindles and EEG slow-wave activity in NREM sleep in mice. Arch Ital Biol 142:511-523.

White TD (1996) Potentiation of excitatory amino acid-evoked adenosine release from rat cortex by inhibitors of adenosine kinase and adenosine deaminase and by acadesine. Eur J Pharmacol 303:27-38.

Yanik G, Glaum S, Radulovacki M (1987) The dose-response effects of caffeine on sleep in rats. Brain Res 403:177-180.

Yee BK, Singer P, Chen JF, Feldon J, Boison D (2007) Transgenic overexpression of adenosine kinase in brain leads to multiple learning impairments and altered sensitivity to psychomimetic drugs. Eur J Neurosci 26:3237-3252.

Zimmermann H (2000) Extracellular metabolism of ATP and other nucleotides. Naunyn Schmiedebergs Arch Pharmacol 362:299-309. 